\title{
LAS MUJERES Y LA PRODUCCION TEXTIL EN LA ROMA ANTIGUA ${ }^{1}$
}

\author{
Silvia Medina Quintana \\ Universidad de Oviedo \\ medinasilvia.uo@uniovi.es
}

Recibido: 27-02-09

Aceptado: 06-03-09

\section{Resumen}

En las sociedades antiguas una de las principales ocupaciones de las mujeres eran los trabajos textiles, tanto desde un punto de vista socioeconómico como simbólico. Los autores antiguos reflejan y favorecen la idea de una mujer virtuosa trabajando en el telar o hilando, imagen muy presente también en la cultura romana. Sin embargo, la epigrafía nos ofrece una visión menos idealizada, pues nos informa de los oficios ejercidos por mujeres de carne y hueso, sobre todo esclavas y personas de condición humilde en la mayoría de los casos.

Palabras clave: mujeres, trabajo textil, virtuosidad, oficios.

\begin{abstract}
In Ancient societies, textile labour was one of the main occupations for women, both from a socioeconomic and symbolic point of view. The idea of a virtuous woman spinning or working at a loom is illustrated and supported in the texts of the ancient

\footnotetext{
${ }^{1}$ Este texto se inscribe dentro del proyecto de I+D del Ministerio de Educación y Ciencia que lleva por título "Maternidad y madres en las culturas grecorromana, oriental y cristiana primitiva. La construcción del paradigma de la feminidad en las sociedades antiguas del Mediterráneo", cuya directora es la doctora Rosa $\mathrm{M}^{\mathrm{a}}$ Cid López. La autora está disfrutando así mismo de una beca predoctoral de la Universidad de Oviedo con la siguiente referencia UNOV-06-BECBOC-9.
} 
authors, also a very frequent image in Roman culture. Nevertheless, epigraphic evidence shows a less idealized picture, as it reveals real-life women who were in most cases slaves or from low class condition.

Key words: Women, textile work, virtue, jobs.

\section{Introducción}

El modelo ideal de feminidad en el mundo antiguo es representado habitualmente a través de una mujer hilando. A lo largo de la Historia, diferentes culturas han concretado en esta actividad el comportamiento idóneo que una mujer debía mostrar: callada, hacendosa, pulcra. Así, el retrato de una fiel Penélope ocupada en su telar nos ha acompañado durante siglos en la imaginería patriarcal que define a la buena esposa, desde las propias sociedades griega y romana hasta el hogar burgués de la contemporaneidad. Quizá por esta razón, en los primeros estudios sobre las mujeres hubo gran interés por analizar la relación entre las féminas y el mundo textil, tanto en lo simbólico y lo que suponía de representación, como en la realidad, es decir, las mujeres que ejercieron dicha actividad (Pomeroy, 1987: 45, 222).

A pesar de que los autores antiguos estaban poco preocupados, en general, por las mujeres y las actividades femeninas, presentaron con asiduidad el trabajo textil como una de las ocupaciones habituales de las mujeres. De igual forma, la figura de las hilanderas está muy presente en la iconografía clásica de la cerámica y los bajorrelieves, tanto en la sociedad griega como en la romana. El huso y la rueca son, así, dos elementos asociados a lo femenino y que aparecen en las manos de mujeres en las representaciones artísticas de diferente naturaleza: obras de teatro, escritos de historia, objetos de la vida cotidiana (vasijas, ánforas, vasos, espejos), ajuares, mosaicos, pinturas murales, relieves de edificios públicos, estelas funerarias...

Se puede que considerar que el trabajo de la lana rompe las barreras sociales y aúna a todas las romanas, pues dicha actividad es rastreable tanto entre las esclavas 
como entre las matronas de elevada posición económica. Sin embargo, veremos que la relación que cada grupo social mantiene respecto a dicha labor difiere enormemente; en el caso de las aristócratas es más un símbolo - especialmente durante finales de la República (133-31 a.C.) y el Alto Imperio (31 a.C.-284 d.C.) - mientras que las esclavas y las mujeres de condición humilde ejercieron tal actividad como un verdadero oficio.

\section{La lanifica: el modelo de mujer en los textos antiguos}

El modelo ideal de la mujer en época romana es el de la matrona: univira (mujer de un solo hombre, al que se mantiene fiel incluso cuando él fallece, permaneciendo viuda), domiseda (que permanece recluida en el ámbito del hogar) y lanifica (hacendosa trabajadora de la lana, símbolo de su castidad y de su virtud). Los textos de los autores antiguos definieron que el comportamiento esperado de una fémina era el de la domesticidad y la piedad, a lo que hay que añadir la lanifica: mujer que trabaja la lana (Martínez, 2005: 172). El cumplimiento de estas características permitiría un hogar en el que reinase la concordia. A estos epítetos hay que añadirle una larga serie de adjetivos rastreables en las inscripciones epigráficas - principalmente en las de carácter funerario -: bondadosa, amable, diligente, fértil, fiel, leal, casta, virtuosa, respetable... (Garrido, 2005: 230).

En el ámbito de la cultura helena el ateniense Jenofonte (431-354 a.C.) regla, en su obra Económico, el modelo que deben cumplir las mujeres virtuosas ${ }^{2}$. Reserva un papel importante para el trabajo textil dentro de las labores a ejercer por la esposa y señora de la casa, y así señala:

\footnotetext{
${ }^{2}$ Este tratado es equiparable a otros textos que, a lo largo de la Historia, pretendieron educar a las mujeres enseñándoles modelos de virtud a cumplir; por ejemplo, La Perfecta Casada de Fray Luis de León (Gil (ed.), 1967: 67).
} 
"Cuando te traigan lana debes cuidar de que se hagan vestidos a los que lo precisen" $"$.

Como continuador de las ideas de Jenofonte en la cultura romana, el agrónomo Columela (principios del siglo I d.C.-70 d.C.) mantiene este adoctrinamiento de las labores a ejercer por la casera en su obra Los doce libros de agricultura. De igual modo que hicieron otros autores coetáneos, Columela critica a los propietarios que viven en la ciudad, arriendan sus parcelas y en vez de trabajar la tierra directamente, la explotan a través de esclavos y colonos. Está recogiendo una situación habitual en Roma ya desde el siglo IV a.C., la de los ricos propietarios absentistas que prefieren ser terratenientes a labradores. A los ojos de Columela, también las esposas de los propietarios son merecedoras de reproche por abandonar el modelo de la matrona del pasado:

"Pero ahora que la mayoría de las mujeres están entregadas al lujo y a la ociosidad, de tal manera que ni aún se dignan tomar el cuidado de preparar la lana y hacerla hilar y tejer, y les molesta llevar vestidos de telas hechas en casa, (...) no es maravilla que les fatigue el cuidado del campo y de los instrumentos de la labor, y que tengan por una cosa molesta el estar unos pocos días en la casería"4.

Lamenta que ese comportamiento de la lanifica sea ahora desdeñado por las mujeres de la aristocracia, de cuyas obligaciones debe encargarse la mujer del capataz, la casera:

"Habiendo olvidado enteramente aquella costumbre antigua de las madres de familia sabinas o romanas, se ha introducido por necesidad que el cuidado de la casera se extienda a ejercer las funciones de aquellas" $"$.

\footnotetext{
${ }^{3}$ Jenofonte, Económico, VII, 36.

${ }^{4}$ Columela, Los doce libros de la agricultura, XII, Prefacio.

${ }^{5}$ Columela, op. cit., XII, Prefacio.
} 
Con anterioridad a la obra de Columela, los ideólogos y escritores al servicio del Estado Romano intentaron fomentar el renacer de los valores antiguos. Así, dentro de la propaganda política promovida por Octavio Augusto (63 a.C.-14 d.C.) durante el Principado, la imagen decorosa que debían ofrecer las mujeres de la familia Iulia ocupaba un lugar destacado. Según relata el biógrafo e historiador Cayo Suetonio (70140 d.C.), Augusto quiso ofrecer una imagen respetable de la familia imperial presentando a las mujeres de la misma como hacendosas tejedoras:

“Educó a su hija y a sus nietas acostumbrándolas incluso al trabajo de la lana y prohibiéndoles toda palabra o actuación encubierta y que no pudiera consignarse en el diario de la casa"6.

En otro fragmento, además de incidir en la virtuosidad de las mujeres, Suetonio refleja a Augusto como un político austero, al no ceder a la ostentación en el vestir:

"Rara vez utilizó otro vestido que el de estar por casa, confeccionado por su hermana, su mujer, su hija y sus nietas",7.

Como sucedía en Roma, la imagen de la mujer tejiendo, u ocupada en el telar, representa toda una serie de valores y supone una carga simbólica tan fuerte que pervivirá - como representación y realidad - a lo largo de toda la Historia.

\footnotetext{
${ }^{6}$ Suetonio, Vida de los Doce Césares. Augusto, 64,2.

${ }^{7}$ Suetonio, Vida de los Doce Césares. Augusto, 73.
} 


\section{EI trabajo textil femenino a través de la epigrafía}

Para conocer los trabajos femeninos de época romana es necesario acercarse a la epigrafía, pues ofrece, en principio, una visión menos idealista que la mostrada por los autores antiguos; sin embargo, también conlleva una serie de limitaciones. Por un lado, debemos considerar que las manifestaciones epigráficas fueron habituales en la Antigüedad, pero para erigir los epígrafes era necesaria cierta capacidad económica, que poseían tanto personas particulares (no exclusivamente de la aristocracia, ya que un número elevado de libertos/as fueron dedicantes de epígrafes) como organismos institucionales o asociaciones privadas (por ejemplo, el Senado, los Collegia...). Esto implica la ausencia mayoritaria de testimonios por parte de las personas con menos capacidad económica (personas libres empobrecidas y esclavos/as), aunque existieron excepciones.

Por otro lado, el material epigráfico del que disponemos es sólo una parte del producido en la Roma Antigua, lo que puede provocar errores de interpretación. Se corre el peligro de generalizar una información proporcionada por un determinado epígrafe o, al contrario, de rechazar alguna hipótesis por no aparecer reflejada en los catálogos epigráficos - lo que no tendría que ser síntoma de su inexistencia, sino simplemente, de que no quedó reflejado.

Además, es preciso recordar que el material epigráfico responde, en cierta medida, a representaciones, pues, como medio oficial de expresión, en ocasiones los epígrafes pudieron acercarse más a modelos o a estereotipos que a la realidad social de las personas reflejadas en ellos (Bodel, 2001: 113).

Sin embargo, y a pesar de los mencionados inconvenientes, la epigrafía ha servido como herramienta para acercarse a la historia de las mujeres. De este modo, algunos historiadores se valieron de las inscripciones epigráficas para conocer los trabajos desempeñados por las mujeres en la antigua Roma, tarea difícil de cumplir si se hubieran valido únicamente de los textos legados por los autores antiguos. 
En los años sesenta del pasado siglo XX Joël Le Gall hizo un breve repertorio de diferentes oficios desarrollados por las mujeres en la Roma Antigua, gracias a la información epigráfica. En dicho artículo, "Métiers de femmes au Corpus Inscriptionum Latinarum", reconoce la importancia que el trabajo de la lana tenía en la sociedad para las mujeres, tanto desde un punto de vista social como económico y menciona oficios más o menos habituales, como el de lanipenda, mujer que trabaja la lana, la quasillaria, hilandera y la sarcinatrix, costurera o zurcidora (Le Gall, 1969: 123 y 124). También nombra una auri vestrix, llamada Sellia Epyre, quien estaría involucrada en el comercio de telas de lujo, y menciona el oficio de auri netrix, bordadora en oro (Le Gall, 1969: 125). Se trata de casos menos habituales, y de los que no hay ejemplos en Hispania.

El artículo de Le Gall fue importante en su época, pues puso de manifiesto que el mundo laboral femenino no se podía reducir únicamente a los hombres, libres o de condición servil ${ }^{8}$. Sin embargo, unos años más tarde, Susan Treggiari realizó un estudio más completo sobre las mujeres trabajadoras romanas, que aún permanece vigente ${ }^{9}$. De los oficios que menciona, extraeremos, en el siguiente apartado, las principales actividades relacionadas con el trabajo textil.

\section{El trabajo textil en la sociedad romana}

La evolución del trabajo textil corre paralela a la propia evolución humana, y se tiene constancia de trabajo textil ya desde épocas prehistóricas. Las distintas sociedades a lo largo de la Historia fueron desarrollando aparatos y utensilios para la

\footnotetext{
${ }^{8}$ En sus propias palabras: «Nous avons trop tendance à reagir vis-á-vis de ces populations urbaines, comme si elles avaient été exclusivement masculines et comme si elles n'avaient compris que de riches, parasites et des esclaves : non, elles comptaient aussi des hommes libres que travaillaient pour gagner leur vie et dont les femmes ne pouvaient pas toujours se permettre de vivre chez elle en se contentant d'y filer la laine » (Le Gall, 1969: 129).

${ }^{9}$ Me refiero, en concreto, a sus artículos: "Jobs for Women" (1976) y "Lower Class Women in the Roman Economy" (1979).
} 
confección de prendas de abrigo, al mismo tiempo que experimentaban con diferentes tejidos ${ }^{10}$.

Aunque en la antigua Roma la lana y el lino fuesen los materiales más trabajados, no se pueden olvidar otros menos habituales, pero de los que se tiene constancia se emplearon para confeccionar textiles: cáñamo, seda, hoja de palmera, esparto, junco... (Alfaro, 1997: 15). Tanto en la Península Itálica como en otras zonas sometidas al poder de Roma - aunque el número de ejemplos con que contamos sea menor - las mujeres se dedicaban al trabajo textil (Pelletier, 1984: 56).

Parte del proceso de trabajo de la lana es el hilado, desempeñado en la sociedad romana fundamentalmente por mujeres, las quasillariae. Lo desarrollaban tanto en sus propias casas, como en pequeños talleres - negocios familiares - o manufacturas de tipo estatal (Pelletier, 1984: 65; Pomeroy, 1987: 222). Y contaban para ello con dos elementos asociados desde la Antigüedad a lo femenino: la rueca - colus y el huso - fusus -, algunos de los cuales han sido encontrados en ajuares funerarios (Alfaro, 1997: 33-37); de hecho, en algunos epitafios se hace referencia al hilado de las mujeres, mientras que el propio Marco Tulio Cicerón (106-43 a.C.) señaló que el huso era para la esposa como el arado para el marido, (Senés, 1995: 72).

Tanto en los hogares rurales como en la ciudad, las mujeres de condición humilde cardaban, hilaban y trabajaban la lana, bien para confeccionar sus propias prendas, para venderlas o para lograr un mínimo salario (Treggiari, 1976: 82; 1979: 67; Martínez, 2002: 83). En este sentido, cabe señalar que el tiempo dedicado por las mujeres a estas actividades puede entenderse como tiempo de trabajo, aunque se desarrollase en momentos sueltos dentro de la jornada habitual y conformara un espacio de sociabilidad femenina; como indica $\mathrm{M}^{\mathrm{a}}$ Dolores Mirón, la actividad pública de los ciudadanos helenos se contrapone al telar femenino, que simboliza la ausencia de

\footnotetext{
${ }^{10}$ Para un recorrido por la historia del tejido, vid. Carmen Alfaro Giner, Tejido y cestería en la Península Ibérica. En dicha obra se analiza la evolución del trabajo y maquinaria textil desde la prehistoria hasta el fin del dominio romano; resulta, además, interesante pues permite realizar analogías con otras partes del Imperio.
} 
alternancia entre tiempo de trabajo y de ocio para las mujeres (Mirón, 2001: 22, 26). De igual forma, Ana Iriarte señala que estas labores femeninas realizadas en grupo son equiparables a la camaradería masculina en los espacios públicos, de los que las mujeres están excluidas. Para esta autora, el vestuario confeccionado por la mujer griega funciona como las paredes de su casa, que la protegen a la vez que la aíslan del mundo exterior (Iriarte y González, 2008: 182, 183).

Existen otras actividades relacionadas con el oficio textil y que pudieron ser ejercidas mayoritariamente por mujeres. En las grandes mansiones aristocráticas, dentro del personal al servicio de las matronas, encontramos las vestiplicae o vestipicae, mujeres encargadas de doblar, guardar y cuidar la ropa, y las vestificae, modistas (Treggiari, 1976: 80, 85) ${ }^{11}$. Sin embargo, las féminas con menos recursos no podían permitirse una modista, por lo que en las zonas urbanas las mujeres compraban la tela y, bien confeccionaban ellas mismas la ropa, o bien se lo encargaban a una sarcinatrix, término que se puede traducir tanto por costurera como por mujer que remienda ropa. (Treggiari, 1979: 68).

La lintearia era la vendedora de lienzo, pero no sólo se encargaba de vender la tela sino también de tejer el lino para confeccionar el lienzo, e incluso podría ofrecer otros tejidos, como algodón o cáñamo. El oficio de lanipenda, mujer que trabaja la lana, hace pensar a Treggiari que la visión de las aristócratas hilando y tejiendo la lana no es más que una representación en el imaginario de la Roma imperial, pues dichas matronas dejarían esas tareas a sus ancillae, sirvientas de condición servil (Treggiari, 1976: 83).

Otro oficio que aparece en las inscripciones es el de purpuraria, o tintorera de telas con púrpura, productos dedicados al mercado de lujo. Parece que esta actividad era ejercida habitualmente por mujeres, aunque también por hombres; es decir, no era exclusivo de las féminas, pero era un oficio que desempeñaban habitualmente, o, al menos, están documentadas varias purpurariae en distintas zonas del Imperio (Gardner, 1990: 238).

\footnotetext{
${ }^{11}$ En la confección de ropa participaban también los varones; son los vestiarii, sastres (Treggiari, 1976: 102).
} 


\title{
5. El ejemplo de Hispania
}

Aunque la llegada de Roma a la Península Ibérica se produjo en el año 218 a.C., la romanización fue un proceso largo y complejo, lo que explica la presencia desigual de material arqueológico, y en concreto, epigráfico. Esto implica que existen más fuentes epigráficas en las zonas más desarrolladas, el sur y el este de la Península, que fueron conquistadas en primer lugar, mientras que en el norte se dispone de un número considerablemente inferior de inscripciones. Si sumamos este inconveniente a los problemas de la epigrafía como fuente, y al hecho de que las mujeres están menos presentes en los testimonios históricos que los varones, se entiende que contemos con tan pocos ejemplos de trabajadoras hispanorromanas relacionadas con el textil.

Dentro de la rama de producción textil existe otra profesión atestiguada en la documentación epigráfica de Hispania, la de sarcinatrix, costurera. Se conserva una inscripción funeraria de Córdoba, datada a finales del siglo I d. C. o principios del siglo II, en la que aparece una familia de libertos vinculada a los Afinii; una de las mujeres mencionadas en este epígrafe, Latinia, es sarcinatrix, pero se desconoce su nombre completo puesto que sólo se conserva del cognomen el principio: "Da[---]". La inscripción entera es:

\author{
M(arcus) Latinius M(arci) [- - - ] \\ L(ucius) Afinius L(uci) l(ibertus) Ata[- - - ] \\ Latinia M(arci) l(iberta) T[- - - ] \\ Demetrius fi[lius] \\ Latinia M(arci) l(iberta) Da[- - - ] \\ sarcinatrix $[---]^{12}$.
}

\footnotetext{
${ }^{12}$ CIL II, 2/7, 339; AE 1981, 502.
} 
Contamos con otro oficio registrado en la epigrafía hispana, el de lintearia, aunque la inscripción, procedente de Tarraco, es muy breve; únicamente aparece escrito el nombre de la mujer, Fulvia, y su profesión, lintearia o vendedora de lienzo ${ }^{13}$.

En un epígrafe hispano aparece claramente la profesión de purpuraria, mientras que en el otro, de Corduba, solo aparece el término purpuraria (o Purpuria), que puede ser el cognomen de la mujer, pues la inscripción se lee mal; quizá el nombre haga referencia a la profesión de la mujer, o se llame así por las tareas que lleva a cabo $^{14}$.

El otro caso, procedente de Gades, es mucho más claro y se trata del epitafio de una purpuraria, Baebia Veneria, a quien su abuelo dedica el monumento; junto a ella está enterrado el que parece su hijo, Baebius Veneriosus, de un año y tres meses. Es interesante destacar que el pequeño lleva tanto su nomen como su cognomen, y no los del padre; la inscripción completa es:

\author{
$D$ (is) M(anibus) s(acrum) \\ B[a]ebia Veneria \\ [- - ] Peraria \\ [c(ara) s(uis)] avo dulcis(simo) \\ ann(orum) $X X V$ \\ $B[a]$ ebius
}

Veneriosus

[a]nn(i) I m(ensium) III s(it) v(obis) t(erra) l(evis $)^{15}$.

\footnotetext{
${ }^{13}$ CIL II, 4318a.

${ }^{14}$ CIL II 2/7, 523; CIL II, 2321.

${ }^{15}$ CIL II 1743.
} 


\section{Conclusiones}

Como ha quedado reflejado a lo largo de este artículo, el telar simbolizaba en las sociedades clásicas la virtud femenina. La vinculación del mismo y de otros objetos textiles (como el huso y la rueca) con las mujeres nace en época antigua, pero pervive durante toda la historia y se perpetúa hasta nuestros días. El cuento infantil de La Bella Durmiente sería sólo un ejemplo de esa sempiterna asociación entre lo femenino - que incluiría, a los ojos de los autores antiguos, domesticidad y debilidad- y las labores textiles ${ }^{16}$.

Sin embargo, gracias a la información epigráfica queda constatado que el trabajo textil supuso en época romana un oficio real ejercido tanto por mujeres como por varones. Contamos con ejemplos escasos en Hispania, en especial si se compara con los oficios masculinos, pero son significativos, pues muestran una sociedad dinámica con una presencia importante de mujeres en el devenir económico y social de la misma. Es decir, que, más allá de las difusas imágenes de virtuosidad creadas por los autores antiguos, en el trabajo del telar se puede rastrear a las mujeres históricas.

\footnotetext{
${ }^{16}$ Precisamente, una de las tareas que las escritoras y asociaciones feministas han venido llevando a cabo son las reescrituras de estos cuentos infantiles tradicionales, en la búsqueda de una educación en igualdad alejada de los estereotipos de género.
} 


\section{BIBLIOGRAFÍA}

- Alfaro Giner, C. (1984): Tejido y cestería en la Península Ibérica. Historia de su técnica e industrias desde la Prehistoria hasta la romanización. Madrid: Instituto Español de Prehistoria.

- Alfaro Giner, C. (1997): El tejido en época romana. Madrid: Arco Libros.

- Bodel, J. (ed.) (2001): Epigraphic evidence. Ancient history form inscriptions. London: Routledge.

- Gardner, J.F. (1990): Women in Roman Law and Society. London: Routledge.

- Garrido, E. (2005): “El modelo de mujer romana en Hispania”. En I. Morant (dir.) Historia de las mujeres en España y América Latina. Vol. I. Madrid : Cátedra, pp. 221239.

- Iriarte, A. y González, M. (2008): Entre Ares y Afrodita. Violencia del erotismo y erótica de la violencia en la Grecia antigua. Madrid: Abada Editores.

- Le Gall, J. (1969): “Métiers de femmes au Corpus Inscriptionum Latinarum”. En Mélanges M. Durry. Revue des Etudes Latines, $\mathrm{n}^{\circ} 47$ bis, pp. 123-130.

- Martínez, C. (2002): “Las relaciones de género en las unidades domésticas campesinas de la Roma antigua". En M $\mathrm{M}^{\mathrm{a}}$ D. Molas Font (ed.), Vivir en femenino. Estudios de mujeres en la antigüedad. Barcelona: Edicions de la Universitat de Barcelona, pp. 6595.

- Martínez, C. (2005): “Los espacios de las mujeres hispanas”. En I. Morant (dir.) Historia de las mujeres en España y América Latina. Vol. I. Madrid : Cátedra, pp.153192.

- Mirón, Ma . D. (2001): “Tiempo de mujeres, tiempo de hombres: género, ocio y trabajo en Grecia antigua". En Arenal, 8:1, pp. 5-37.

- Pelletier, A. (1984) : La femme dans la societé gallo-romaine. Paris : Picard.

- Pomeroy, S. (1987): Diosas, rameras, esposas y esclavas: mujeres en la Antigüedad Clásica. Madrid: Akal. 
- Senés, G. (1995): "La matrona romana: consideraciones sobre la situación de la mujer en Roma”. En M $\mathrm{M}^{\mathrm{a}} \mathrm{D}$. Verdejo (coord.), Comportamientos antagónicos de las mujeres en el Mundo Antiguo. Málaga: Universidad de Málaga, Secretariado de Publicaciones, pp. 69-87.

- Treggiari, S. (1976): “Jobs for Women”. En AJAH, vol. 1, n 2, pp. 76-104.

- Treggiari, S. (1979): “Lower Class Women in the Roman Economy”. En Florilegium, 1, pp. 65-86.

\section{FUENTES}

- Jenofonte: Económico. Edición de Juan Gil de 1967. Madrid: Sociedad de Estudios y Publicaciones.

- Suetonio: Vida de los Doce Césares. Augusto. Edición de Antonio Ramírez de Verger de 1992. Madrid: Gredos.

- Columela: Los doce libros de Agricultura. Edición de Carlos J. Castro de 1959. Barcelona: Iberia. 